\title{
THE EFFECTS OF BIODIESEL BLENDS AND ARCO EC-DIESEL ON EMISSIONS FROM LIGHT HEAVY-DUTY DIESEL VEHICLES
}

Thomas D. Durbin* and Joseph M. Norbeck

Bourns College of Engineering, Center for Environmental Research and Technology (CE-CERT), University of California, Riverside, CA 92521

\begin{abstract}
Chassis dynamometer tests were performed on 7 light heavy-duty diesel trucks comparing the emissions of a California diesel fuel with emissions from 4 other fuels: ARCO EC-diesel (EC-D) and three $20 \%$ biodiesel blends (1 yellow grease and 2 soy-based). The EC-D and the yellow grease biodiesel blend both showed significant reductions in THC and CO emissions over the test vehicle fleet. EC-D also showed reductions in $\mathrm{PM}$ emission rates. $\mathrm{NO}_{\mathrm{x}}$ emissions were comparable for the different fuel types over the range of vehicles tested. The soy-based biodiesel blends did not show significant or consistent emissions differences over all test vehicles. Total carbon accounted for more than $70 \%$ of the PM mass for 4 of the 5 sampled vehicles. Elemental and organic carbon ratios varied significantly from vehicle-to-vehicle but showed very little fuel dependence. Inorganic species represented a smaller portion of the composite total, ranging from 0.2 to $3.3 \%$ of the total PM. Total PAH emissions ranged from approximately $1.8 \mathrm{mg} / \mathrm{mi}$ to 67.8 $\mathrm{mg} / \mathrm{mi}$ over the different vehicle/fuel combinations representing between 1.6 and $3.8 \%$ of the total PM mass.

* corresponding author
\end{abstract}




\subsection{Introduction}

As the impetus to reduce diesel emissions continues, the need to develop more advanced or alternative diesel fuels becomes more important. Two fuels that are being examined to meet these needs include biodiesel and ARCO Emission Control Diesel (EC-D). Biodiesel is renewable and can be produced domestically from sources such as vegetable oils, animal fats, restaurant grease, or other feedstocks. Several legislative measures have been passed promoting the increased use of biodiesel fuels, including a measure to allow fleets to meet alternative fuel vehicle acquisition requirements by using biodiesel added to conventional diesel at blends of $20 \%$ and higher. A number of studies of larger heavy-duty engines and heavy-duty vehicles have shown that biodiesel can provide emissions reductions in hydrocarbons $(\mathrm{HC})$, carbon monoxide $(\mathrm{CO})$ and particulate matter $(\mathrm{PM})$, with some increases observed for nitrogen oxides $\left(\mathrm{NO}_{\mathrm{x}}\right)$ (1-7). Much of this work has focused on comparisons with Federal diesel, however, with limited studies providing comparisons with California Reformulated diesel (CARB)(1,5).

The College of Engineering-Center for Environmental Research and Technology (CE-CERT) at the University of California, Riverside, has conducted some limited studies to evaluate biodiesel fuels in comparison with CARB diesel for light heavy-duty diesel vehicles. For this work, a comparison was made between CARB diesel, a 100\% biodiesel, an 80/20 (CARB/biodiesel) blend and a synthetic diesel for emissions performance (8). Chassis dynamometer tests were performed on four light heavy-duty diesel vehicles using each of the four fuels. The results of this study indicated that biodiesel and biodiesel blends generally lowered THC and CO emissions in comparison with the CARB fuel, while $\mathrm{NO}_{\mathrm{x}}$ emissions were either not significantly different or slightly higher. PM emissions, on the other hand, were generally higher for the biodiesel fuels, in contrast to previous results.

More recently, ARCO has developed a new diesel fuel called Emissions Control Diesel (EC-D). EC-D is produced from typical crude oil using conventional refining processes but is designed to have a sulfur content below $15 \mathrm{ppmw}$ and lower aromatics and a higher cetane number in comparison with typical in-use fuels. The ultra-low sulfur content of the fuel provides a significant 
added benefit in that the fuel can be used in conjunction with sulfur-sensitive emission control devices. A more commercial version of this fuel, called EC-D1, is also available with a sulfur content below 15 ppmw.

EC-D is currently being used in an extensive demonstration program in the Southern California area with an emphasis on using the fuel in conjunction with diesel particulate filters (DPFs) (9). The DPFs include Johnson-Matthey's continuously regenerating technology filter $\left(\mathrm{CRT}^{\mathrm{TM}}\right)$ and Engelhard's catalytic soot filter $\left(\mathrm{DPX}^{\mathrm{TM}}\right)$. Tests of class 8 Ralphs grocery trucks with DPFs showed PM reductions between 91 and $97 \%$ and also significant reductions in THC and CO $(10,11)$. Similar results were also found in tests conducted on tanker trucks, school buses, and refuse trucks $(9,12)$. Emission reductions were also found for the EC-D fuel in comparison with CARB fuel. Ralphs grocery trucks operated on EC-D had average $\mathrm{NO}_{\mathrm{x}}$ emissions $15 \%$ lower than those operated on a CARB fuel. These reductions could not be considered statistically significant, however, due to high vehicle-to-vehicle variability (10). For tanker trucks tested on both CARB fuel and EC-D, emissions were found to be $11 \%$ lower for $\mathrm{NO}_{\mathrm{x}}$ and $3 \%$ lower for PM for the ECD compared with the CARB fuel (9). Similarly, school buses were found to have reductions in $\mathrm{NO}_{\mathrm{x}}$ and PM emissions of 10 and 15\%, respectively, for the EC-D compared with CARB fuel (9). Emission reductions for EC-D in comparison with CARB fuel were also found for refuse trucks (12).

The present program was designed to expand the scope of CE-CERT's previous biodiesel work and provide comparisons with EC-D for light heavy-duty diesel vehicles. This work is a follow-up of CE-CERT's previous biodiesel project (8) and also provides ties to CE-CERTs on-going work in testing Hertz equipment rental trucks as part of the ARCO EC-D demonstration program (9). For this study, the test matrix included 7 light heavy-duty diesel vehicles tested on a series of 5 fuels. The five fuels included an in-use CARB fuel, EC-D, and three 20\% biodiesel blend (1 yellow grease and 2 soy-based). In addition to the regulated emissions, PM samples were collected on a 5 vehicle subset for analysis of chemical composition and PAHs. The results and conclusions of this study are summarized in the following paper. More detailed results for this study are presented in ref. 13 . 


\subsection{Experimental Procedures}

\subsection{Vehicle Recruitment}

A total of 7 light heavy-duty diesel vehicles were recruited for vehicle testing. Six of these vehicles were obtained from the City of San Bernardino, California municipal fleet. The 1983 Ford F250 is an in-house test vehicle. Each vehicle was inspected to establish its general condition and ensure it was safe to test before acceptance into the program. The test vehicles and their characteristics are listed in Table 1.

\subsection{Test Fuels}

Each vehicle was tested on a series of 5 fuels. These fuels were:

- An in-use California diesel fuel (CARB).

- ARCO EC-D fuel. A diesel fuel produced from conventional crude oil refining process targeted to have less than 15 ppm sulfur, less than $10 \%$ aromatics by volume, and a nominal cetane number of 60 .

- A blend of $80 \%$ CARB fuel and $20 \%$ SoyGold biodiesel. The CARB fuel was the in-use fuel listed above. The SoyGold biodiesel was a soy-based biodiesel produced by Ag Processing, Inc. and distributed by Radtke \& Tomberlin Distribution, Inc., Leawood, KS.

- A blend of $80 \%$ CARB fuel and 20\% World Energy biodiesel. The CARB fuel was the in-use fuel listed above. The World Energy biodiesel was a soy-based biodiesel produced by Procter \& Gamble and distributed by World Energy Alternatives, Cambridge, MA.

- A blend of $80 \%$ CARB fuel and $20 \%$ OXyG B-60 biodiesel. The CARB fuel was the in-use fuel listed above. The OXyG B-60 was a yellow grease biodiesel produced and distributed by Southern States Power Co., Ontario, CA.

A summary of the specifications for each of the neat test fuels is provided in Table 2 with more complete fuel specifications provided in ref. 13. In this listing, several properties in particular are notable. The ARCO EC-diesel fuel has an aromatic content considerably lower than that of the inuse CARB fuel with a low sulfur content. The biodiesel fuels have negligible aromatic and sulfur contents as neat fuels (14). The biodiesel blends with the CARB fuel have aromatic and sulfur contents closer to those of the CARB fuel, however. The cetane numbers are also considerably different for the fuels tested. In particular, the cetane numbers for the EC-diesel and OXyG B-60 were both greater than 60 while those of the CARB fuel and the other two biodiesel fuels were in the low 50s. 


\subsection{Protocol for Vehicle Testing}

All vehicles were tested over the FTP to obtain mass emission rates for total PM, THC, CO, and $\mathrm{NO}_{\mathrm{x}}$. THC measurements were collected using a heated sample line as specified in the Code of Federal Regulations (CFR) for diesel vehicles (\$86.110-94). Vehicles were preconditioned prior to the first test on any new fuel by driving over two back-to-back iterations of the LA4 driving schedule on the dynamometer followed by an overnight soak at a temperature of approximately $72^{\circ} \mathrm{F}$. Each vehicle was tested at least twice on each of the 5 test fuels. In a few cases additional tests were conducted to verify the observed emissions trends. All tests were conducted in CECERT's Vehicle Emission Research Laboratory (VERL) equipped with a Burke E. Porter 48-inch single-roll electric dynamometer and a 12-inch diameter tunnel for diesel vehicles.

To meet the program objectives regarding fuel effects on reactivity and toxicity, additional sampling was conducted for a subset of the FTP tests. PM samples were collected for analysis of elemental and organic carbon, trace elements and metals, and ions on 5 of the 7 test vehicles. Polyaromatic hydrocarbon (PAH) samples were also collected on these same vehicles. On two vehicles, gas-phase samples were collected for analysis of $\mathrm{C}_{1}-\mathrm{C}_{12}$ hydrocarbon species and $\mathrm{C}_{1}-\mathrm{C}_{8}$ carbonyls. The details of these results are provided in ref 13. Analyses of the PAHs and PM composition were done by the Desert Research Institute (DRI), Reno, NV. Table 3 shows the type of analyses conducted for each vehicle. The additional analyses discussed above were all performed for at least one test per fuel type.

\subsection{Particulate Sample Collection}

The sampling protocol for this project was designed to provide mass emissions rates, size distributions, and samples for analysis for PM composition. The dilution tunnel used for sampling was fitted with three sampling probes located approximately 130 inches downstream of the exhaust mixing flange. The sampling configuration, filter media, and analyses to be performed are summarized below:

- Probe 1 was fitted with 47 mm, $2.0 \mu \mathrm{m}$ Gelman Teflon membrane filters using a Pierburg PM sampling system to obtain total PM mass emission rates for each phase of the FTP. Each filter assembly was fitted with a primary and a backup filter. 
- Probe 2 was fitted with a two-way flow splitter that was used to collect samples for PM composition analyses for 5 of the test vehicles. For these tests, one filter holder was fitted with $47 \mathrm{~mm}, 2.0 \mu \mathrm{m}$ Gelman Teflon membrane filters for analysis of trace elements and ions. A second filter holder was fitted with prefired Pallflex 2500 QAT-UP quartz fiber filters for organic and elemental carbon analyses, and detailed speciation of the PM PAHs. Thin stainless steel rings were placed in front of the quartz fiber filters to provide a more uniform and well defined deposit for carbon analysis. The quartz filters were backed up using a vapor-phase trap for collection of semi-volatile PAHs consisting of XAD-4 resin (polystyrene, divinylbenzene polymer) sandwiched between two polyurethane foam plugs (PUF).

- Probe 3 was fitted with a Microorifice Uniform Deposit Impactor (MOUDI) for collection of size segregated samples. For this project, MOUDI samples were collected on a subset of samples. The experimental procedures used for the MOUDI and the size distribution results are discussed in greater detail in ref. 13.

For each test, mass emission rates were determined for each phase of the FTP. Samples for chemical analysis on quartz-fiber filters, PUF/XAD substrate, and Teflon membrane filters were collected cumulatively over the entire FTP. Chemical analyses were performed on samples from one test for each vehicle/fuel combination for the 5 test vehicles specified in Table 3. All samples were collected at 20 liters per minute $(\mathrm{lpm})$ with the exception of the MOUDI, which was operated at $30 \mathrm{lpm}$. All flows were measured and controlled using mass flow controllers, and all sampling is performed under isokinetic conditions using removable probe tips.

\subsection{Particulate Sample Analysis}

Teflon membrane filters were weighted before and after sampling to determine the collected mass using an ATI Orion ultra-microbalance. The microbalance is located in an environmental weighing chamber maintained at a temperature of $25.3 \pm 0.6^{\circ} \mathrm{C}$ and a relative humidity of $44 \pm 6 \%$. Before and at the completion of sample collection, substrates were preconditioned for at least 24 hours in the environmental chamber before weighing. Tunnel blanks were collected weekly throughout testing and used to correct the PM mass emission rates. Tunnel blanks were converted to mass emission rates based on sample flows and the length of the testing period.

The Teflon membrane filters collected from probe 2 were utilized for chemical analysis of metals and other trace elements, and sulfate, nitrate, and ammonium ions. All analyses were conducted 
by DRI. Samples were stored in petri dishes in a refrigerator prior to shipment to DRI. Shipment to DRI was in a cooler with blue ice packs. Metals and other trace elements were analyzed using $\mathrm{x}$-ray fluorescence (XRF). Teflon filters were extracted in a 60:40 mixture of isopropyl alcohol and distilled, deionized water for nitrate and sulfate analyses using ion chromatography. A separate extraction with distilled, deionized water was used for analysis of ammonium ions, since the isopropyl alcohol causes interference in the measurement of this ion. Ammonium ions were measured using automated colorimetry.

The quartz fiber filters collected at probe 2 were used for elemental and organic carbon analyses. Quartz fiber filters were obtained from DRI after prefiring at $900^{\circ} \mathrm{C}$ for three hours to reduce background carbon levels. The filters were shipped in blue ice to CE-CERT and stored in a refrigerator until used. Following sample collection, filters were stored in a freezer in petri dishes lined with aluminum foil prior to return shipment to DRI in a cooler with blue ice packs. Elemental and organic carbon analyses were performed by DRI using the Thermal Optical Reflectance (TOR) method (15). Analyses were performed on an approximately $0.512 \mathrm{~cm}^{2}$ punch from the filter.

PAH analyses were performed on the PUF/XAD vapor-phase trap and quartz fiber filters. PUF/XAD backup cartridges were utilized to collect semi-volatile PAHs. XAD resin and PUF cartridges were obtained precleaned from DRI. The XAD resin was cleaned by washing with distilled water and methanol, followed by Soxhlet extraction for 48 hours with methanol. The XAD was then drained and Soxhlet extracted for an additional 48 hours with dichloromethane $\left(\mathrm{CH}_{2} \mathrm{Cl}_{2}\right)$. The resin was dried in a vacuum oven at $50^{\circ} \mathrm{C}$. A second Soxhlet extraction was then performed with dichloromethane for 48 hours. PUF cartridges were cleaned by first washing with distilled water, followed by Soxhlet extraction in acetone for 48 hours, followed by Soxhlet extraction for 48 hours in $10 \%$ diethyl ether in hexane. The extracted PUFs were then dried in a vacuum oven at $50^{\circ} \mathrm{C}$ for approximately 3 days. XAD resin and PUF cartridges were stored in a freezer before and after sampling prior to return to DRI. XAD and PUF filters were shipped to CE-CERT from DRI, and from CE-CERT back to DRI in a cooler with blue ice.

For the sample analysis, the PUF plugs were Soxhlet extracted with $10 \%$ diethyl ether in hexane, while the filters and XAD resin were microwave extracted with dichloromethane. The combined 
extract was then reduced to a volume of $\sim 1 \mathrm{ml}$ by rotary evaporation and analyzed by gas chromatograph/mass spectrometer (GC/MS) in selected ion monitoring mode.

\subsection{Emissions Test Results}

\subsection{Mass Emission Results}

The FTP weighted gaseous and PM mass emission rates for each vehicle/fuel combination are presented in Figures 1-4. These data represent the average of all tests conducted for each vehicle/fuel combination. The error bars in Figures 1-4 were calculated from the replicate tests for each vehicle/fuel combination as 2 times the standard deviation of the mean. It should be noted that the THC and PM emissions for the 1993 Ford F350 are divided by a factor of five in Figures 1 and 3, respectively, to allow the details in the emissions changes for the lower emitting vehicles to be more clearly presented. Complete FTP data for each vehicle and fuel are presented in ref. 13.

The strongest fuel effect was observed for THC and CO emissions, as shown in Figures 1 and 2. Specifically, the EC-D and OXyG B-60 biodiesel blend both showed significant reductions in these emissions for most of the test vehicles. THC emissions reductions ranged from approximately 32 to $56 \%$ for the EC-D compared with CARB fuel, with THC emissions for ECD and CARB fuel comparable for the 1990 Ford E350. Five of the 7 vehicles showed THC emission reductions for the OXyG B-60 biodiesel blend ranging from 21 to $66 \%$ compared with the CARB fuel. The magnitude of many of these changes was also generally greater than the error bars indicating statistical significance. Significant reductions in THC emissions were found for the soy-based biodiesel fuels compared with the CARB fuel for the 1993 Ford F350 (the vehicle with the highest THC emissions) and the 1990 Chevrolet 2500. On the other hand, THC emissions were slightly higher for the soy-based biodiesel blend for the 1987 Chevrolet C-30 and the 1989 Chevrolet 2500. THC emissions for the soy-based biodiesel blends for the other test vehicles were comparable with those of the baseline CARB fuel.

$\mathrm{CO}$ emissions reductions were also relatively dramatic for the EC-D and OXyG B-60 fuel with reductions relative to the CARB fuel ranging from 12 to $41 \%$ for the EC-D and from 0 to $46 \%$ 
for the OXyG B-60. Again, these reductions were greater than the experimental error in most cases. CO emissions for the soy-based biodiesel fuels were lower compared with the CARB fuel for the 1993 Ford F350 and 1990 Chevy 2500. For the other test vehicles, however, CO emissions were comparable with those of the CARB fuel.

Regarding THC and CO emissions, several other points are worth mentioning. The fuels with the best emissions for THC and CO (EC-D and OXy-G B-60) both had cetane numbers greater than 60 while the other fuels had cetane numbers in the low 50s. It should also be noted that the OXyG B-60 fuel is present in only a $20 \%$ blend, as opposed to EC-D that is not a blend. Thus, if higher blend ratios of OXyG B-60 were used, it is possible that even greater reductions in these emissions might also be achieved.

Some fuel effects were also observed for PM emission rates. The EC-D fuel showed the most significant reductions in PM emission rates. The largest and most significant PM reductions for EC-D were observed for the 1987 Chevy C-30 and the 1993 Ford F350, which were $30 \%$ and $43 \%$ compared with the CARB fuel, respectively. The remaining vehicles showed reductions in the 5 to $20 \%$ range for EC-D with some of the differences within the experimental variability. The OXyG B-60 showed some promise in reducing PM emissions for the highest emitting vehicle, the 1993 Ford F350, and the 1983 Ford F250, although the latter results were not statistically significant. PM emissions over the remaining vehicles were comparable overall with those of the CARB fuel. The soy-based biodiesel blends had higher PM emissions rates than the CARB fuel for 4 of the 7 vehicles, with roughly comparable PM emission rates for the remaining three vehicles. This is consistent with the results of our previous study on light heavy-duty diesel vehicles that showed a tendency for higher PM emissions with the soy-based biodiesel blends (8). It is worth noting that studies of heavier duty diesel engines in different testing configurations, i.e., engine dynamometer and opacity testing, have indicated opposite trends with PM emissions being reduced with biodiesel fuels (1-7). Additional testing is probably needed to determine the nature of these discrepancies, which could include differences in the duty cycle for the light heavyduty diesel vehicles.

$\mathrm{NO}_{\mathrm{x}}$ emissions were comparable for the different fuel types over the range of vehicles tested. The 1990 Ford E350 showed the most significant differences between different fuel types, with EC-D 
and OXyG B-60 $\mathrm{NO}_{\mathrm{x}}$ emissions being lower than those for the other fuels. For this vehicle, the CARB fuel was tested over two testing periods, leading to the relatively large error bars. For some vehicles, the biodiesel fuels also showed some slight increases in $\mathrm{NO}_{\mathrm{x}}$ although these increases were generally within the experimental error. It should be noted that other studies have shown that biodiesel blends can increase $\mathrm{NO}_{\mathrm{x}}(1-8)$. Although some increases were observed for $100 \%$ biodiesel in our previous work, no significant differences were observed for the B20 blends (8).

\subsection{Particulate Chemical Species}

For the 5 vehicles specified in Table 3, chemical analyses of the PM were performed on one test for each vehicle/fuel combination to determine emissions for elemental and organic carbon, ions, and trace elements. The mass emissions results for each of the tests are presented in Table 4. The mass emission rates for individual chemical species are corrected for the contribution of trace components found in tunnel blanks. The full results including measurement uncertainties are presented in ref. 13. Chemical components whose concentrations are at least twice the analytical uncertainty are shown in bold.

Table 5 gives the fractions of total carbon, inorganic compounds, and PAHs as percentage of total PM, and gives elemental carbon and organic carbon as a percentage of total carbon. Note since the chemical analysis samples were collected cumulatively over the FTP, these percentages are based on cumulative PM mass over the entire FTP rather than FTP weighted values. The results show that elemental and organic carbon are the primary constituents for diesel particulate, consistent with the observations of other researchers (16-20). Total carbon accounted for more than $70 \%$ of the PM mass for 4 of the 5 test vehicles. The elemental and organic fractions varied significantly from vehicle to vehicle but showed very little fuel dependence. The vehicles with the highest PM mass emission rates also showed the largest percentage of organic carbon relative to elemental carbon. The EC-D fuel had the highest percentage of elemental carbon for 4 of the 5 vehicles, but these differences were very small for all but one vehicle. The other fuels showed no significant trends over the 5 vehicles.

Inorganic species including ions and elements represented a smaller portion of the composite total, ranging from 0.2 to $3.3 \%$ of the total particulate. All inorganic species had emission rates of 
less than $1 \mathrm{mg} / \mathrm{mi}$ for each test vehicle, with the only species with average emission rates of greater than $0.1 \mathrm{mg} / \mathrm{mi}$ for each of the test vehicles being $\mathrm{SO}_{4}{ }^{2-}, \mathrm{NH}_{4}{ }^{+}, \mathrm{Mg}, \mathrm{Si}, \mathrm{P}, \mathrm{S}, \mathrm{Cl}, \mathrm{Ca}$, and Zn. The 1990 Ford E350 had the highest emission rate for elements and ions on a percentage basis while the 1983 Ford F250 had the highest emission rates for elements and ions on a mg/mi basis. Interestingly, the 1993 Ford F350 with the highest emission rate for total PM had relatively low emissions of PM elements and ions. For each test vehicle, EC-D had the lowest emission rates for $\mathrm{S}$ and $\mathrm{SO}_{4}{ }^{2-}$, consistent with the lower sulfur levels found in this fuel. The World Energy biodiesel blend also had a tendency for higher emissions rates of elements and ions relative to the other fuels, with element and ion emission rates more than twice those of the other fuels for 3 of the 5 vehicles sampled.

\subsection{PAH Emission Results}

PAH emissions are presented in Table 6 for each of the 5 test vehicles. This Table includes nearly 40 of the PAHs with the highest emission rates averaged over the 5 vehicles. A more complete listing of the PAH species is provided in ref. 13.

Total PAH emissions ranged from approximately $1.8 \mathrm{mg} / \mathrm{mi}$ to $67.8 \mathrm{mg} / \mathrm{mi}$ over the different vehicle/fuel combinations. PAHs represented between 1.6 and 3.8\% of the total PM mass over the 5 vehicles. For 3 of the 5 vehicles, EC-D had the lowest PAH emissions. This is consistent with the lower PAH content of EC-D relative to the CARB fuel. For the other two vehicles, the World Energy biodiesel blend and OXyG B-60 biodiesel blend had the lowest emissions although EC-D had the second-lowest emissions. The biodiesel blends generally had emissions comparable to or lower than the CARB fuel, although for two vehicle/fuel combinations a biodiesel blend had higher PAH emissions than the CARB fuel.

Naphthalene, 1-methylnaphthalene, 2-methylnaphthalene were the three most significant PAH species averaged over all five vehicles. Other PAHs present at levels greater than twice the standard deviations included biphenyl, methylbiphenyls, dimethylnaphthalenes, and trimethylnaphthalenes. 


\subsection{Acknowledgments}

The authors acknowledge the contribution and support of the following individuals during the course of this project. Dave Martis, Kathalena Cocker, Joseph Calhoun, and Ross Rettig of the Vehicle Emissions Research Laboratory (CE-CERT) performed the emissions testing on the vehicles. Clifton Frazier, Barbara Zielinska, Barbara Hinsvark and Ewa Uberna of the Desert Research Institute performed the particulate chemical analyses. We thank the South Coast Air Quality Management District for its financial support of this project under contract no. 99120.

\subsection{References}

1. Clark, N.N.; Atkinson, C.M.; Thompson, G.J.; and Nine, R.D. Transient Emissions Comparisons of Alternative Compression Ignition Fuel; SAE Technical Paper No. 1999-011117; Society of Automotive Engineers: Warrendale, PA, 1999.

2. Graboski, M.S.; Ross, J.D.; and McCormick, R.L. Transient Emissions from No. 2 diesel and Biodiesel Blends in a DDC Series 60 Engine; SAE Technical Paper No. 961166; Society of Automotive Engineers: Warrendale, PA, 1996.

3. McDonald, J.F.; Purcell, D.L.; McClure, B.T.; and Kittelson, D.B. Emissions Characteristics of Soy Methyl Ester Fuels in an IDI Compression Ignition Engine; SAE Technical Paper No. 950400; Society of Automotive Engineers: Warrendale, PA, 1995.

4. Smith, J.A.; Endicott, D.L.; and Graze, R.R. Biodiesel Engine Performance and Emissions Testing. Final Report prepared for the National Biodiesel Board, Jefferson City, MO, by Caterpillar, May 1998.

5. Starr, M.E. Influence on Transient Emissions at Various Injection Timings, using Cetane Improvers, Biodiesel, and Low Aromatic Fuels; SAE Technical Paper No. 972904; Society of Automotive Engineers: Warrendale, PA, 1997. 
6. Sharp, C.A. Characterization of Biodiesel Exhaust Emissions for EPA 211(b), Final Report for the National Biodiesel Board, Jefferson City, MO, by Southwest Research Institute, San Antonio, TX, January 1998.

7. Wang, W.G., Lyons, D.W., Clark, N.N., and Gautum, M. Environ. Sci. Technol. 2000, 34, 933.

8. Durbin, T.D., Collins, J.R., Norbeck, J.M., and Smith, M.R. (2000a) Environ. Sci. Technol. 2000, 34, 349.

9. LeTavec, C; Uihlein, J., Segal, J.; and Vertin, K. EC-Diesel Technology Validation Program Interim Report; SAE Technical Paper No. 2000-01-1854; Society of Automotive Engineers: Warrendale, PA, 2000.

10. Clark, N.N., Boyce, J.E., Xie, W., Gautam, M., Lyons, D.W., Vertin, K., LeTavec, C.A., Coburn, T.C., (2000) Class 8 Trucks Operating on Ultra-Low Sulfur Diesel With Particulate filter Systems: Regulated Emissions, SAE Technical Paper No. 2000-01-2815.

11. Vertin, K., Chandler, K., LeTavec, C., Goguen, S., Keske-Hynnila, D., Chatterjee, S., Smith, G., and Hallstrom, K. Class 8 Trucks Operating on Ultra-Low Sulfur diesel with Particulate Filter Systems: A Fleet Start-Up Experience; SAE Technical Paper No. 2000-01-2821; Society of Automotive Engineers: Warrendale, PA, 2000.

12. Chatterjee, S., McDonald, C., Conway, R., Windawi, H., Vertin, K., LeTavec, C.A., Clark, N.N., Gautam, M., Emission Reductions and Operational Experiences with Heavy Duty Diesel Fleet Vehicles Retrofitted with Continuously Regenerated Diesel Particulate Filters in Southern California; SAE Technical Paper No. 2001-01-0512; Society of Automotive Engineers: Warrendale, PA, 2001.

13. Durbin, T.D., Cocker, K., Collins, J.F., Norbeck, J.M., Evaluation of the Effects of Biodiesel and Biodiesel Blends on Exhaust Emission Rates and Reactivity - 2 Final report for the South Coast Air Quality Management District under contract no. 99120, by University of California, Riverside, CE-CERT, July 2001. 
14. Howell, S. Biodiesel Production and Specifications, Proceedings of the Biodiesel 'B20' Workshop, Diamond Bar, CA, July 1999.

15. Chow, J.C., Watson, J.G., Pritchaett, L.C., Pierson, W.R., Frazier, C.A., and Purcell, R.G. Atmos. Env. 1993, 27A, 1185.

16. Cadle, S.H.; Mulawa, P.A.; Hunsanger, E.C.; Nelson, K.; Ragazzi, R.; Barrett, R.; Gallagher, G.; Lawson, D.R.; Knapp, K.T.; and Snow, R. Measurement of Particulate Matter Emissions from In-Use Light-Duty Motor Vehicles in the Denver, Colorado Area, Final Report for the Coordinating Research Council, Alpharetta, GA, under project E-24-1, March 1998.

17. Durbin, T.D.; Norbeck, J.M.; Smith, M.R, and Truex, T.J. Environ. Sci. Technol. 1999, 33, 4401.

18. Hildemann, L.M.; Markowski, G.R.; and Cass, G.R. Environ. Sci. Technol. 1991, 25, 744.

19. Watson, J.G.; Chow, J.C.; Lowenthal, D.H.; Pritchett, L.C.; Frazier, C.A.; Neuroth, G.R.; and Robbins, R. Atmos. Env. 1994, 28, 2493.

20. Whitney, K.A., Characterization of Particulate Exhaust Emissions from In-Use Light-Duty Vehicles; Final Report for the Coordinating Research Council, Alpharetta, GA, under project E-24-1, November 1998. 
Table 1. Vehicle Descriptions for Test Fleet

\begin{tabular}{lllccc}
\hline $\begin{array}{c}\text { Model Make } \\
\text { Year }\end{array}$ & Model & $\begin{array}{c}\text { Odometer } \\
\text { (miles) }\end{array}$ & Engine & $\begin{array}{c}\text { Fuel, Air } \\
\text { System }\end{array}$ \\
\hline 1993 & Ford & F-350 PU & 26784 & 7.3 liter Navistar V8 & IDI, no-turbo \\
1990 & Ford & E-350 Van & 88534 & 7.3 liter Navistar V8 & IDI, no-turbo \\
1990 & Chevy & 2500 PU & $90448^{*}$ & 6.2 liter GM V8 & IDI, no-turbo \\
1989 Chevy & 2500 PU & 140752 & 6.2 liter GM V8 & IDI, no-turbo \\
1987 Chevy & C-30 PU & 88170 & 6.2 liter GM V8 & IDI, no-turbo \\
1985 & Chevy & C-20 PU & 67796 & 6.2 liter GM V8 & IDI, no-turbo \\
1983 Ford & F-250 PU & 74235 & 6.9 liter Navistar V8 & IDI, no-turbo \\
\hline
\end{tabular}

IDI = Indirect Fuel injection, PU=pick-up, * odometer non operational when tested 
Table 2. Selected Fuel Properties

\begin{tabular}{lccccc}
\hline & CARB & EC-D & SoyGold & World Energy & OXyG B-60 \\
\hline API gravity & 37.8 & 42.6 & NA & NA & NA \\
Aromatics, vol. \% & 22.9 & 10.86 & NA & NA & NA \\
PNAs, wt. \% & 3.7 & 0.9 & NA & NA & NA \\
Cetane index & 51.3 & & & & \\
Cetane number & & 63.4 & 52.3 & 52.9 & 61.9 \\
\multicolumn{1}{c}{ Distillation, T50, ${ }^{\circ} \mathrm{F}$} & 508 & 530 & $\mathrm{NA}$ & $\mathrm{NA}$ & $\mathrm{NA}$ \\
& 620 & 618 & & & \\
Free glycerin, mass $\%$ & $\mathrm{NA}$ & $\mathrm{NA}$ & 0.002 & 0.001 & 0.002 \\
Total glycerin, mass $\%$ & $\mathrm{NA}$ & $\mathrm{NA}$ & 0.228 & 0.122 & 0.156 \\
Sulfur, ppm & 72 & 3 & $0.000 \%$ & $0.000 \%$ & $0.000 \%$ \\
\hline
\end{tabular}

Notes: NA = not available. The glycerin test is applicable to only the biodiesel fuels. Biodiesel is approximately a single boiling point compound, and thus distillation tests are not applicable. Biodiesel also includes nonaromatic compounds that interfere with the standard method for measuring aromatics. Biodiesel is expected to have negligible level of aromatics, however.

Table 3. Sample Collection and Analysis Matrix

\begin{tabular}{lccccc}
\hline & \multicolumn{2}{c}{ FTP 3 phase } & \multicolumn{2}{c}{ Cumulative over 3 phases } \\
\hline Vehicle & $\begin{array}{c}\text { PM, } \\
\text { gases }\end{array}$ & $\begin{array}{c}\mathbf{C}_{\mathbf{1}}-\mathbf{C}_{\mathbf{4}}, \\
\mathbf{C}_{\mathbf{4}} \text { - C Carbonyls }\end{array}$ & $\begin{array}{c}\text { Ions, XRF } \\
\text { EC, OC }\end{array}$ & PAH \\
\hline 93 Ford F-350 & $\checkmark$ & & $\checkmark$ & $\checkmark$ \\
90 Ford E-350 & $\checkmark$ & & & $\checkmark$ \\
90 Chevy 2500 & $\checkmark$ & & & $\checkmark$ & $\checkmark$ \\
89 Chevy 2500 & $\checkmark$ & $\checkmark$ & $\checkmark$ & & \\
87 Chevy C-30 & $\checkmark$ & & & $\checkmark$ & $\checkmark$ \\
85 Chevy C-20 & $\checkmark$ & & & $\checkmark$ & $\checkmark$ \\
83 Ford F-250 & $\checkmark$ & $\checkmark$ & $\checkmark$ & $\checkmark$ & $\checkmark$ \\
\hline
\end{tabular}


Table 4. PM Emission Rates for Chemical Species (mg/mi)

\begin{tabular}{|c|c|c|c|c|c|c|c|c|c|c|c|c|c|c|c|c|}
\hline \multirow{2}{*}{$\begin{array}{c}\text { vehicle } \\
\text { fuel }\end{array}$} & \multicolumn{5}{|c|}{1989 Chevy 2500} & \multicolumn{6}{|c|}{1993 Ford F350 } & \multicolumn{5}{|c|}{1990 Ford E350 } \\
\hline & CARB & EC-D & OXyG & SoyGold & Energy & CARB & EC-D & OXyG & \multicolumn{2}{|c|}{ SoyGold } & $\begin{array}{l}\text { World } \\
\text { Energy }\end{array}$ & CARB & EC-D & OXyG & SoyGold & $\begin{array}{c}\text { World } \\
\text { Energy }\end{array}$ \\
\hline Organic C & 176.0 & 110.9 & 153.9 & 201.0 & 192.6 & 1167.1 & 627.8 & 961.4 & \multicolumn{2}{|c|}{1211.2} & 1513.9 & 96.4 & 74.3 & 89.8 & 77.1 & 70.8 \\
\hline Elemental C & 29.4 & 70.5 & 43.7 & 31.5 & 40.3 & 71.5 & 40.4 & 58.1 & \multicolumn{2}{|l|}{63.5} & 54.2 & 25.5 & 41.9 & 33.2 & 35.0 & 36.5 \\
\hline Total C & 205.4 & 181.4 & 197.6 & 232.5 & 232.9 & 1238.6 & 668.2 & 1019.5 & \multicolumn{2}{|l|}{1274.7} & 1568.1 & 121.9 & 116.1 & 123.0 & 112.2 & 107.3 \\
\hline $\mathrm{Cl}^{-}$ & 0.0 & 0.1 & 0.0 & 0.0 & 0.1 & 0.0 & 0.0 & 0.0 & \multicolumn{2}{|l|}{0.1} & 0.0 & 0.0 & 0.1 & 0.1 & 0.1 & 0.2 \\
\hline $\mathrm{NO}_{3^{-}}$ & 0.2 & 0.3 & 0.2 & 0.2 & \multirow{2}{*}{0.8} & 0.4 & 0.4 & 0.3 & \multicolumn{2}{|l|}{0.4} & 0.6 & 0.3 & 0.4 & 0.3 & 0.3 & 1.2 \\
\hline $\mathrm{SO}_{4}{ }^{2-}$ & 0.4 & 0.3 & 0.4 & 0.5 & & 0.5 & 0.5 & 0.5 & \multicolumn{2}{|l|}{0.6} & 1.1 & 0.7 & 0.4 & 0.8 & 0.9 & 1.5 \\
\hline $\mathrm{NH}_{4+}$ & 0.3 & 0.2 & 0.2 & 0.1 & $\begin{array}{l}1.0 \\
0.2\end{array}$ & 0.1 & 0.2 & 0.1 & \multicolumn{2}{|l|}{0.1} & 0.1 & 0.2 & 0.2 & 0.2 & 0.3 & 0.3 \\
\hline Mg & 0.0 & 0.0 & 0.1 & 0.0 & 0.2 & 0.1 & 0.1 & 0.1 & \multicolumn{2}{|l|}{0.1} & 0.1 & 0.1 & 0.1 & 0.1 & 0.1 & 0.3 \\
\hline $\mathbf{S i}$ & 0.5 & 0.6 & 0.5 & 0.4 & 0.5 & 0.2 & 0.3 & 0.2 & \multicolumn{2}{|l|}{0.2} & 0.2 & 0.3 & 0.2 & 0.2 & 0.2 & 0.2 \\
\hline $\mathbf{P}$ & 0.1 & 0.1 & 0.1 & 0.1 & 0.6 & 0.1 & 0.1 & 0.1 & 0.1 & & 0.4 & 0.2 & 0.3 & 0.2 & 0.2 & 0.7 \\
\hline $\mathbf{S}$ & 0.4 & 0.3 & 0.4 & 0.4 & 0.6 & 0.6 & 0.4 & 0.6 & 0.5 & & 0.6 & 0.4 & 0.3 & 0.4 & 0.4 & 0.5 \\
\hline Cl & 0.1 & 0.1 & 0.0 & 0.1 & 0.1 & 0.1 & 0.1 & 0.1 & 0.1 & & 0.1 & 0.0 & 0.1 & 0.1 & 0.1 & 0.2 \\
\hline $\mathrm{Ca}$ & 0.1 & 0.2 & 0.2 & 0.2 & 1.5 & 0.3 & 0.2 & 0.3 & 0.3 & & 1.2 & 0.4 & 0.5 & 0.4 & 0.5 & 1.9 \\
\hline $\mathbf{F e}$ & 0.0 & 0.1 & 0.0 & 0.0 & 0.1 & 0.1 & 0.1 & 0.2 & 0.0 & & 0.1 & 0.0 & 0.0 & 0.1 & 0.0 & 0.1 \\
\hline $\mathrm{Zn}$ & 0.2 & 0.2 & 0.2 & 0.2 & 0.2 & 0.3 & 0.2 & 0.3 & 0.3 & & 0.2 & 0.4 & 0.5 & 0.4 & 0.4 & 0.4 \\
\hline $\mathbf{P b}$ & 0.0 & 0.0 & 0.0 & 0.0 & 0.0 & 0.0 & 0.0 & 0.1 & 0.0 & & 0.1 & 0.0 & 0.0 & 0.0 & 0.0 & 0.0 \\
\hline & & hicle & & & 1985 Chev & vy C-20 & & & & & 198 & Ford F2: & & & & \\
\hline & & fuel & CARB & EC-D & OXyG S & SoyGold & World & hergy & CARB & EC-D & OXyG & SoyG & & World En & & \\
\hline & Orga & ic $\mathbf{C}$ & 91.5 & 75.6 & 80.0 & 76.9 & 88 & & 505.3 & 379.1 & 466.4 & 584 & & 634.2 & & \\
\hline & Elem & tal C & 105.3 & 86.3 & 116.9 & 88.0 & 84 & & 41.7 & 36.3 & 40.3 & 33 & & 32.2 & & \\
\hline & Total & & 196.8 & 161.9 & 196.9 & 164.9 & 17 & & 547.0 & 415.4 & 506.6 & 618 & & 666.4 & & \\
\hline & $\mathrm{Cl}^{-}$ & & 0.1 & 0.0 & 0.0 & 0.0 & 0 & & 0.1 & 0.1 & 0.0 & 0.1 & & 0.1 & & \\
\hline & $\mathrm{NO}_{3}-$ & & 0.2 & 0.1 & 0.3 & 0.2 & 0 & & 0.5 & 0.7 & 0.7 & 0.8 & & 1.4 & & \\
\hline & $\mathrm{SO}_{4}{ }^{2-}$ & & 0.4 & 0.1 & 0.4 & 0.4 & 0 & & 1.4 & 0.9 & 1.2 & 1.3 & & 2.0 & & \\
\hline & $\mathbf{N H}_{4+}$ & & 0.2 & 0.1 & 0.2 & 0.2 & 0 & & 0.2 & 0.2 & 0.2 & 0.2 & & 0.3 & & \\
\hline & Mg & & 0.0 & 0.0 & 0.0 & 0.0 & 0 & & 0.1 & 0.1 & 0.1 & 0.0 & & 0.1 & & \\
\hline & $\mathrm{Si}$ & & 0.5 & 0.4 & 0.5 & 0.4 & 0 & & 0.2 & 0.1 & 0.1 & 0.1 & & 0.2 & & \\
\hline & $\mathbf{P}$ & & 0.1 & 0.1 & 0.1 & 0.1 & 0 & & 0.5 & 0.6 & 0.5 & 0.6 & & 0.8 & & \\
\hline & $\mathbf{S}$ & & 0.3 & 0.2 & 0.4 & 0.4 & 0 & & 1.0 & 0.8 & 0.9 & 1.1 & & 1.1 & & \\
\hline & $\mathrm{Cl}$ & & 0.0 & 0.0 & 0.1 & 0.1 & 0 & & 0.2 & 0.2 & 0.2 & 0.2 & & 0.2 & & \\
\hline & $\mathrm{Ca}$ & & 0.1 & 0.1 & 0.1 & 0.2 & 1. & & 1.6 & 1.6 & 1.7 & 1.8 & & 2.8 & & \\
\hline & $\mathrm{Fe}$ & & 0.0 & 0.0 & 0.0 & 0.0 & 0 & & 0.1 & 0.1 & 0.1 & 0.1 & & 0.2 & & \\
\hline & $\mathbf{Z n}$ & & 0.2 & 0.2 & 0.2 & 0.2 & 0 . & & 1.1 & 1.1 & 1.1 & 1.3 & & 1.4 & & \\
\hline
\end{tabular}


Table 5. Particle Mass Fractions

\begin{tabular}{|c|c|c|c|c|c|c|c|}
\hline Vehicle & Fuel & $\begin{array}{c}\text { FTP PM } \\
\mathrm{mg} / \mathrm{mi}\end{array}$ & $\begin{array}{c}\text { OC } \\
\% \text { of TC }\end{array}$ & $\begin{array}{c}\text { EC } \\
\% \text { of TC }\end{array}$ & $\begin{array}{c}\text { TC } \\
\% \text { of PM }\end{array}$ & $\begin{array}{c}\text { Elements } \\
+ \text { Ions } \\
\% \text { of PM }\end{array}$ & $\begin{array}{c}\text { Total } \\
\text { PAH } \\
\% \text { of PM }\end{array}$ \\
\hline 1993 Ford F350 & CARB & 2281.7 & 94.2 & 5.8 & 55.2 & 0.1 & $3.0 \%$ \\
\hline 1993 Ford F350 & EC-D & 1291.9 & 94.0 & 6.0 & 55.6 & 0.2 & $1.3 \%$ \\
\hline 1993 Ford F350 & OXyG blend & 1830.2 & 94.3 & 5.7 & 61.4 & 0.2 & $1.7 \%$ \\
\hline 1993 Ford F350 & SoyGold blend & 2578.1 & 95.0 & 5.0 & 51.0 & 0.1 & $1.9 \%$ \\
\hline \multirow[t]{2}{*}{1993 Ford F350 } & W.E.blend & 2773.4 & 96.5 & 3.5 & 56.9 & 0.2 & $0.8 \%$ \\
\hline & Average & 2151.1 & $94.8 \%$ & $5.2 \%$ & $56.0 \%$ & $0.2 \%$ & $1.8 \%$ \\
\hline 1990 Ford E350 & CARB & 126.6 & 79.0 & 21.0 & 92.0 & 2.4 & $3.7 \%$ \\
\hline 1990 Ford E350 & EC-D & 118.8 & 64.0 & 36.0 & 91.2 & 2.4 & $2.3 \%$ \\
\hline 1990 Ford E350 & OXyG blend & 127.8 & 73.0 & 27.0 & 93.0 & 2.5 & $1.4 \%$ \\
\hline 1990 Ford E350 & SoyGold blend & 116.7 & 68.8 & 31.2 & 91.7 & 2.8 & $2.7 \%$ \\
\hline \multirow[t]{2}{*}{1990 Ford E350 } & W.E.blend & 116.1 & 66.0 & 34.0 & 91.8 & 6.3 & $3.6 \%$ \\
\hline & Average & 121.2 & $70.2 \%$ & $29.8 \%$ & $91.9 \%$ & $3.3 \%$ & $2.7 \%$ \\
\hline 1989 Chevy 2500 & CARB & 221.1 & 85.7 & 14.3 & 78.9 & 0.9 & $4.8 \%$ \\
\hline 1989 Chevy 2500 & EC-D & 182.1 & 61.1 & 38.9 & 82.3 & 1.1 & $4.9 \%$ \\
\hline 1989 Chevy 2500 & OXyG blend & 256.3 & 77.9 & 22.1 & 74.5 & 0.9 & $4.5 \%$ \\
\hline 1989 Chevy 2500 & SoyGold blend & 271.8 & 86.4 & 13.6 & 73.0 & 0.9 & $4.0 \%$ \\
\hline \multirow[t]{2}{*}{1989 Chevy 2500} & W.E.blend & 268.1 & 82.7 & 17.3 & 74.0 & 1.9 & $0.9 \%$ \\
\hline & Average & 239.9 & $78.8 \%$ & $21.2 \%$ & $76.5 \%$ & $1.1 \%$ & $3.8 \%$ \\
\hline 1985 Chevy C-20 & CARB & 220.6 & 46.5 & 53.5 & 91.8 & 1.0 & $2.9 \%$ \\
\hline 1985 Chevy C-20 & EC-D & 188.9 & 46.7 & 53.3 & 84.4 & 0.7 & $1.5 \%$ \\
\hline 1985 Chevy C-20 & OXyG blend & 206.4 & 40.6 & 59.4 & 93.2 & 1.2 & $3.9 \%$ \\
\hline 1985 Chevy C-20 & SoyGold blend & 193.9 & 46.6 & 53.4 & 84.2 & 1.1 & $2.2 \%$ \\
\hline \multirow[t]{2}{*}{1985 Chevy C-20 } & W.E.blend & 197.5 & 51.2 & 48.8 & 87.7 & 2.7 & $2.5 \%$ \\
\hline & Average & 201.5 & $46.3 \%$ & $53.7 \%$ & $88.3 \%$ & $1.3 \%$ & $2.6 \%$ \\
\hline 1983 Ford F250 & CARB & 616.5 & 92.4 & 7.6 & 72.6 & 0.9 & $2.1 \%$ \\
\hline 1983 Ford F250 & EC-D & 526.7 & 91.3 & 8.7 & 76.7 & 1.2 & $0.9 \%$ \\
\hline 1983 Ford F250 & OXyG blend & 575.3 & 92.1 & 7.9 & 92.1 & 1.2 & \\
\hline 1983 Ford F250 & SoyGold blend & 808.1 & 94.6 & 5.4 & 61.8 & 0.7 & $2.0 \%$ \\
\hline \multirow[t]{2}{*}{1983 Ford F250 } & W.E.blend & 915.4 & 95.2 & 4.8 & 62.0 & 1.0 & $1.5 \%$ \\
\hline & Average & 688.4 & $93.1 \%$ & $6.9 \%$ & $73.0 \%$ & $1.0 \%$ & $1.6 \%$ \\
\hline
\end{tabular}


Table 6. PAH Emission Rates (mg/mi)

\begin{tabular}{|c|c|c|c|c|c|c|c|c|c|c|c|c|c|c|c|}
\hline \multirow{2}{*}{$\begin{array}{c}\text { vehicle } \\
\text { fuel }\end{array}$} & \multicolumn{5}{|c|}{1989 Chevy 2500} & \multicolumn{5}{|c|}{1993 Ford F350 } & \multicolumn{5}{|c|}{1990 Ford E350 } \\
\hline & CARB & EC-D & OXyG & SoyGold & $\begin{array}{l}\text { World } \\
\text { Energy }\end{array}$ & CARB & EC-D & OXyG & SoyGold & $\begin{array}{l}\text { World } \\
\text { Energy }\end{array}$ & CARB & EC-D & OXyG & SoyGold & $\begin{array}{l}\text { World } \\
\text { Energy }\end{array}$ \\
\hline Total PAHs & 12.43 & 10.89 & 11.92 & 12.64 & 2.72 & 67.77 & 15.76 & 28.69 & 46.72 & 23.31 & 4.95 & 2.97 & 1.82 & 3.34 & 4.17 \\
\hline Naphthalene & 3.85 & 4.91 & 4.03 & 4.09 & 1.42 & 6.82 & 3.16 & 3.37 & 4.55 & 2.28 & 2.32 & 1.97 & 0.74 & 2.08 & 2.39 \\
\hline 1-methylnaphthalene & 1.32 & 1.07 & 1.29 & 1.13 & 0.12 & 9.59 & 1.51 & 3.41 & 6.04 & 1.65 & 0.29 & 0.17 & 0.20 & 0.30 & 0.12 \\
\hline $\begin{array}{l}\text { 2-methylnaphthalene } \\
1,3+1,6+1,7-\end{array}$ & 0.92 & 0.80 & 0.84 & 0.74 & -0.15 & 7.80 & 1.31 & 2.90 & 5.23 & 1.35 & 0.15 & 0.04 & 0.01 & 0.12 & -0.03 \\
\hline dimethylnaphthalene & 0.57 & 0.27 & 0.56 & 0.71 & -0.08 & 7.59 & 1.24 & 2.51 & 4.91 & 0.37 & 0.13 & 0.04 & -0.06 & -0.06 & 0.08 \\
\hline 3-methylbiphenyl & 0.59 & 0.37 & 0.48 & 0.50 & 0.20 & 3.16 & 1.20 & 1.36 & 2.20 & 1.01 & 0.28 & 0.14 & 0.07 & 0.16 & 0.23 \\
\hline 2,6+2,7-dimethylnaphthalene & 0.25 & 0.11 & 0.23 & 0.33 & -0.04 & 4.58 & 0.68 & 1.33 & 2.71 & 0.14 & 0.05 & 0.02 & -0.03 & -0.03 & 0.06 \\
\hline Biphenyl & 0.35 & 0.22 & 0.28 & 0.34 & 0.02 & 2.15 & 0.56 & 0.81 & 1.44 & 0.31 & 0.06 & 0.03 & 0.03 & 0.04 & 0.05 \\
\hline 4-methylbiphenyl & 0.25 & 0.19 & 0.20 & 0.22 & 0.12 & 1.46 & 0.51 & 0.54 & 0.96 & 0.46 & 0.14 & 0.08 & 0.03 & 0.09 & 0.09 \\
\hline $\begin{array}{l}\text { A-trimethylnaphthalene } \\
1,4+1,5+2,3-\end{array}$ & 0.20 & 0.08 & 0.20 & 0.27 & 0.00 & 1.80 & 0.41 & 1.02 & 1.50 & 0.40 & 0.06 & 0.02 & 0.01 & 0.01 & 0.04 \\
\hline dimethylnaphthalene & 0.20 & 0.09 & 0.18 & 0.22 & -0.02 & 2.34 & 0.38 & 0.80 & 1.47 & 0.13 & 0.04 & 0.01 & -0.01 & -0.01 & 0.02 \\
\hline B-trimethylnaphthalene & 0.20 & 0.07 & 0.19 & 0.24 & 0.01 & 1.46 & 0.32 & 0.94 & 1.32 & 0.48 & 0.07 & 0.02 & 0.02 & 0.02 & 0.05 \\
\hline bibenz & 0.12 & 0.03 & 0.11 & 0.11 & 0.05 & 1.04 & 0.21 & 0.57 & 0.87 & 1.53 & 0.10 & 0.07 & 0.21 & 0.20 & 0.13 \\
\hline 2-methylbiphenyl & 0.22 & 0.15 & 0.15 & 0.16 & 0.06 & 0.58 & 0.52 & 0.31 & 0.49 & 0.37 & 0.34 & 0.11 & 0.03 & 0.07 & 0.40 \\
\hline 1+2-ethylnaphthalene & 0.13 & 0.13 & 0.19 & 0.25 & -0.01 & 2.04 & 0.37 & 0.62 & 1.28 & 0.10 & 0.04 & 0.02 & -0.01 & -0.01 & 0.02 \\
\hline C-trimethylnaphthalene & 0.18 & 0.05 & 0.16 & 0.21 & -0.01 & 1.34 & 0.27 & 0.79 & 1.14 & 0.43 & 0.06 & 0.01 & 0.01 & 0.01 & 0.04 \\
\hline Phenanthrene & 0.39 & 0.34 & 0.39 & 0.42 & 0.05 & 0.93 & 0.19 & 0.47 & 0.61 & 0.56 & 0.09 & 0.03 & 0.03 & 0.03 & 0.04 \\
\hline 2,3,5-trimethylnaphtha & 0.14 & 0.02 & 0.11 & 0.15 & -0.02 & 1.12 & 0.18 & 0.69 & 0.96 & 0.59 & 0.04 & -0.01 & 0.01 & 0.01 & 0.02 \\
\hline Acenaphthylene & 0.42 & 0.93 & 0.68 & 0.60 & 0.03 & 0.22 & 0.10 & 0.13 & 0.14 & 0.12 & 0.04 & 0.03 & 0.04 & 0.07 & 0.05 \\
\hline E-trimethylnaphthalene & 0.13 & 0.03 & 0.11 & 0.14 & 0.00 & 0.85 & 0.19 & 0.59 & 0.83 & 0.35 & 0.04 & 0.01 & 0.01 & 0.01 & 0.02 \\
\hline Fluorene & 0.17 & 0.15 & 0.18 & 0.17 & 0.06 & 0.45 & 0.12 & 0.28 & 0.34 & 1.14 & 0.03 & 0.01 & 0.08 & 0.08 & 0.03 \\
\hline F-trimethylnaphthalene & 0.11 & 0.03 & 0.09 & 0.11 & 0.00 & 0.75 & 0.16 & 0.45 & 0.63 & 0.48 & 0.03 & 0.00 & 0.02 & 0.02 & 0.02 \\
\hline C-dimethylphenanthrene & 0.06 & 0.02 & 0.05 & 0.07 & 0.05 & 0.73 & 0.09 & 0.32 & 0.45 & 0.70 & 0.03 & 0.01 & 0.03 & 0.02 & 0.02 \\
\hline 1,2-dimethylnaphthalene & 0.08 & 0.06 & 0.08 & 0.09 & 0.00 & 0.80 & 0.15 & 0.28 & 0.51 & 0.08 & 0.03 & 0.01 & 0.00 & 0.00 & 0.01 \\
\hline 2-methylphenanthrene & 0.08 & 0.03 & 0.06 & 0.07 & 0.02 & 0.52 & 0.10 & 0.24 & 0.34 & 0.48 & 0.04 & 0.02 & 0.03 & 0.02 & 0.02 \\
\hline A-methylphenanthrene & 0.07 & 0.03 & 0.05 & 0.07 & 0.02 & 0.49 & 0.09 & 0.24 & 0.32 & 0.59 & 0.04 & 0.02 & 0.03 & 0.02 & 0.02 \\
\hline Pyrene & 0.20 & 0.21 & 0.20 & 0.20 & 0.14 & 0.29 & 0.14 & 0.18 & 0.22 & 0.20 & 0.02 & 0.01 & 0.01 & 0.01 & 0.02 \\
\hline 1-Methylfluorene & 0.04 & 0.02 & 0.05 & 0.06 & 0.00 & 0.50 & 0.07 & 0.25 & 0.37 & 0.53 & 0.04 & 0.01 & 0.01 & 0.01 & 0.01 \\
\hline C-methylphenanthrene & 0.06 & 0.03 & 0.05 & 0.07 & 0.02 & 0.52 & 0.09 & 0.24 & 0.34 & 0.44 & 0.03 & 0.02 & 0.02 & 0.02 & 0.02 \\
\hline J-trimethylnaphthalene & 0.03 & 0.02 & 0.06 & 0.08 & 0.03 & 0.59 & 0.10 & 0.30 & 0.48 & 0.18 & 0.05 & 0.01 & 0.00 & 0.02 & 0.01 \\
\hline 4-methylpyrene & 0.04 & 0.03 & 0.03 & 0.04 & 0.04 & 0.34 & 0.18 & 0.19 & 0.26 & 0.63 & 0.01 & 0.00 & 0.01 & 0.00 & 0.00 \\
\hline A-methylfluorene & 0.04 & 0.02 & 0.04 & 0.04 & 0.00 & 0.42 & 0.08 & 0.24 & 0.37 & 0.35 & 0.03 & 0.01 & 0.01 & 0.01 & 0.01 \\
\hline D-MePy/MeFl & 0.04 & 0.02 & 0.03 & 0.04 & 0.04 & 0.34 & 0.17 & 0.18 & 0.24 & 0.58 & 0.01 & 0.00 & 0.01 & 0.01 & 0.01 \\
\hline 1-methylphenanthrene & 0.04 & 0.02 & 0.04 & 0.05 & 0.02 & 0.41 & 0.07 & 0.20 & 0.26 & 0.42 & 0.02 & 0.01 & 0.02 & 0.01 & 0.00 \\
\hline 2,4,5-trimethylnaphtha & 0.05 & 0.01 & 0.04 & 0.06 & 0.01 & 0.38 & 0.06 & 0.23 & 0.32 & 0.24 & 0.03 & 0.00 & 0.01 & 0.01 & 0.01 \\
\hline 1,7-dimethylphenanthre & 0.03 & 0.01 & 0.03 & 0.03 & 0.03 & 0.38 & 0.05 & 0.17 & 0.21 & 0.38 & 0.02 & 0.01 & 0.02 & 0.01 & 0.01 \\
\hline 9-anthraldehyde & 0.04 & 0.01 & 0.02 & 0.03 & 0.04 & 0.25 & 0.04 & 0.12 & 0.18 & 0.48 & 0.01 & 0.01 & 0.02 & 0.01 & 0.02 \\
\hline 1-methylpyrene & 0.02 & 0.02 & 0.02 & 0.03 & 0.03 & 0.24 & 0.12 & 0.13 & 0.18 & 0.47 & 0.01 & 0.00 & 0.00 & 0.00 & 0.00 \\
\hline Acenaphthene & 0.05 & 0.00 & 0.00 & 0.03 & 0.02 & 0.18 & 0.13 & 0.11 & 0.15 & 0.11 & 0.09 & 0.07 & -0.01 & 0.01 & -0.01 \\
\hline
\end{tabular}


Table 6. PAH Emission Rates (mg/mi)

\begin{tabular}{|c|c|c|c|c|c|c|c|c|c|c|}
\hline \multirow{2}{*}{$\begin{array}{c}\text { vehicle } \\
\text { fuel }\end{array}$} & \multicolumn{5}{|c|}{1985 Chevy C-20 } & \multicolumn{5}{|c|}{1983 Ford F250 } \\
\hline & CARB & EC-D & OXyG & SoyGold & $\begin{array}{l}\text { World } \\
\text { Energy }\end{array}$ & CARB & EC-D & OXyG & SoyGold & $\begin{array}{l}\text { World } \\
\text { Energy }\end{array}$ \\
\hline Total PAHs & 6.22 & 2.79 & 8.33 & 4.39 & 4.85 & 16.02 & 4.81 & NA & 20.02 & 15.59 \\
\hline Naphthalene & 3.16 & 1.86 & 5.81 & 2.52 & 2.94 & 2.67 & 1.77 & NA & 3.83 & 3.34 \\
\hline 1-methylnaphthalene & 0.32 & 0.07 & 0.19 & 0.20 & 0.19 & 2.00 & 0.53 & NA & 2.12 & 1.33 \\
\hline $\begin{array}{l}\text { 2-methylnaphthalene } \\
1,3+1,6+1,7-\end{array}$ & 0.00 & -0.19 & -0.11 & -0.09 & -0.07 & 1.58 & 0.33 & NA & 1.93 & 1.14 \\
\hline dimethylnaphthalene & 0.17 & -0.08 & 0.09 & 0.11 & 0.10 & 0.57 & 0.21 & NA & 1.48 & 1.22 \\
\hline 3-methylbiphenyl & 0.50 & 0.26 & 0.60 & 0.28 & 0.27 & 1.20 & 0.42 & NA & 1.00 & 0.78 \\
\hline 2,6+2,7-dimethylnaphthalene & 0.06 & -0.04 & 0.03 & 0.04 & 0.03 & 0.25 & 0.10 & NA & 0.73 & 0.58 \\
\hline Biphenyl & 0.14 & 0.04 & 0.11 & 0.12 & 0.12 & 0.54 & 0.13 & NA & 0.48 & 0.39 \\
\hline 4-methylbiphenyl & 0.21 & 0.16 & 0.32 & 0.13 & 0.13 & 0.50 & 0.18 & NA & 0.42 & 0.33 \\
\hline $\begin{array}{l}\text { A-trimethylnaphthalene } \\
1,4+1,5+2,3-\end{array}$ & 0.06 & 0.00 & 0.04 & 0.05 & 0.05 & 0.29 & 0.08 & NA & 0.59 & 0.49 \\
\hline dimethylnaphthalene & 0.06 & -0.02 & 0.03 & 0.04 & 0.04 & 0.21 & 0.07 & NA & 0.47 & 0.38 \\
\hline B-trimethylnaphthalene & 0.06 & 0.00 & 0.04 & 0.05 & 0.05 & 0.36 & 0.07 & NA & 0.59 & 0.46 \\
\hline Bibenz & 0.03 & 0.03 & 0.05 & 0.01 & 0.01 & 0.52 & 0.03 & NA & 0.36 & 0.33 \\
\hline 2-methylbiphenyl & 0.47 & 0.09 & 0.32 & 0.13 & 0.13 & 0.30 & 0.19 & NA & 0.62 & 0.28 \\
\hline 1+2-ethylnaphthalene & 0.08 & 0.00 & 0.04 & 0.05 & 0.04 & 0.10 & 0.08 & NA & 0.36 & 0.31 \\
\hline C-trimethylnaphthalene & 0.05 & 0.00 & 0.03 & 0.04 & 0.03 & 0.36 & 0.05 & NA & 0.53 & 0.40 \\
\hline Phenanthrene & 0.13 & 0.07 & 0.12 & 0.12 & 0.13 & 0.31 & 0.04 & NA & 0.36 & 0.21 \\
\hline 2,3,5-trimethylnaphtha & 0.02 & -0.02 & 0.01 & 0.01 & 0.00 & 0.46 & 0.02 & NA & 0.47 & 0.33 \\
\hline Acenaphthylene & 0.17 & 0.20 & 0.13 & 0.19 & 0.19 & 0.15 & 0.03 & NA & 0.08 & 0.08 \\
\hline E-trimethylnaphthalene & 0.03 & 0.00 & 0.02 & 0.02 & 0.02 & 0.28 & 0.03 & NA & 0.37 & 0.28 \\
\hline Fluorene & 0.04 & 0.13 & 0.04 & 0.04 & 0.04 & 0.40 & 0.02 & NA & 0.21 & 0.13 \\
\hline F-trimethylnaphthalene & 0.02 & 0.01 & 0.01 & 0.02 & 0.01 & 0.32 & 0.03 & NA & 0.32 & 0.22 \\
\hline C-dimethylphenanthrene & 0.03 & 0.02 & 0.03 & 0.02 & 0.03 & 0.21 & 0.02 & NA & 0.16 & 0.16 \\
\hline 1,2-dimethylnaphthalene & 0.03 & 0.00 & 0.02 & 0.02 & 0.02 & 0.09 & 0.03 & NA & 0.19 & 0.15 \\
\hline 2-methylphenanthrene & 0.04 & 0.03 & 0.04 & 0.03 & 0.04 & 0.16 & 0.02 & NA & 0.16 & 0.13 \\
\hline A-methylphenanthrene & 0.04 & 0.03 & 0.04 & 0.03 & 0.04 & 0.14 & 0.02 & NA & 0.14 & 0.12 \\
\hline Pyrene & 0.05 & 0.03 & 0.04 & 0.05 & 0.05 & 0.13 & 0.04 & NA & 0.08 & 0.08 \\
\hline 1-Methylfluorene & 0.02 & 0.01 & 0.02 & 0.01 & 0.01 & 0.15 & 0.01 & NA & 0.21 & 0.14 \\
\hline C-methylphenanthrene & 0.03 & 0.01 & 0.02 & 0.02 & 0.02 & 0.15 & 0.02 & NA & 0.14 & 0.12 \\
\hline J-trimethylnaphthalene & 0.02 & 0.01 & 0.01 & 0.01 & 0.01 & 0.06 & 0.02 & NA & 0.21 & 0.18 \\
\hline 4-methylpyrene & 0.01 & 0.01 & 0.01 & 0.01 & 0.01 & 0.12 & 0.03 & NA & 0.08 & 0.08 \\
\hline A-methylfluorene & 0.01 & 0.00 & 0.02 & 0.02 & 0.01 & 0.11 & 0.01 & NA & 0.19 & 0.12 \\
\hline D-MePy/MeFl & 0.02 & 0.01 & 0.01 & 0.01 & 0.01 & 0.11 & 0.03 & NA & 0.08 & 0.08 \\
\hline 1-methylphenanthrene & 0.02 & 0.01 & 0.02 & 0.01 & 0.02 & 0.12 & 0.01 & NA & 0.12 & 0.10 \\
\hline 2,4,5-trimethylnaphtha & 0.02 & 0.01 & 0.01 & 0.01 & 0.01 & 0.14 & 0.01 & NA & 0.17 & 0.12 \\
\hline 1,7-dimethylphenanthre & 0.02 & 0.01 & 0.02 & 0.01 & 0.01 & 0.11 & 0.02 & NA & 0.08 & 0.08 \\
\hline 9-anthraldehyde & 0.02 & 0.01 & 0.01 & 0.01 & 0.01 & 0.09 & 0.01 & NA & 0.06 & 0.08 \\
\hline 1-methylpyrene & 0.01 & 0.00 & 0.01 & 0.01 & 0.01 & 0.07 & 0.02 & NA & 0.05 & 0.06 \\
\hline Acenaphthene & 0.00 & 0.01 & 0.01 & 0.01 & 0.02 & 0.13 & 0.09 & NA & 0.07 & 0.17 \\
\hline
\end{tabular}


FTP THC Emissions

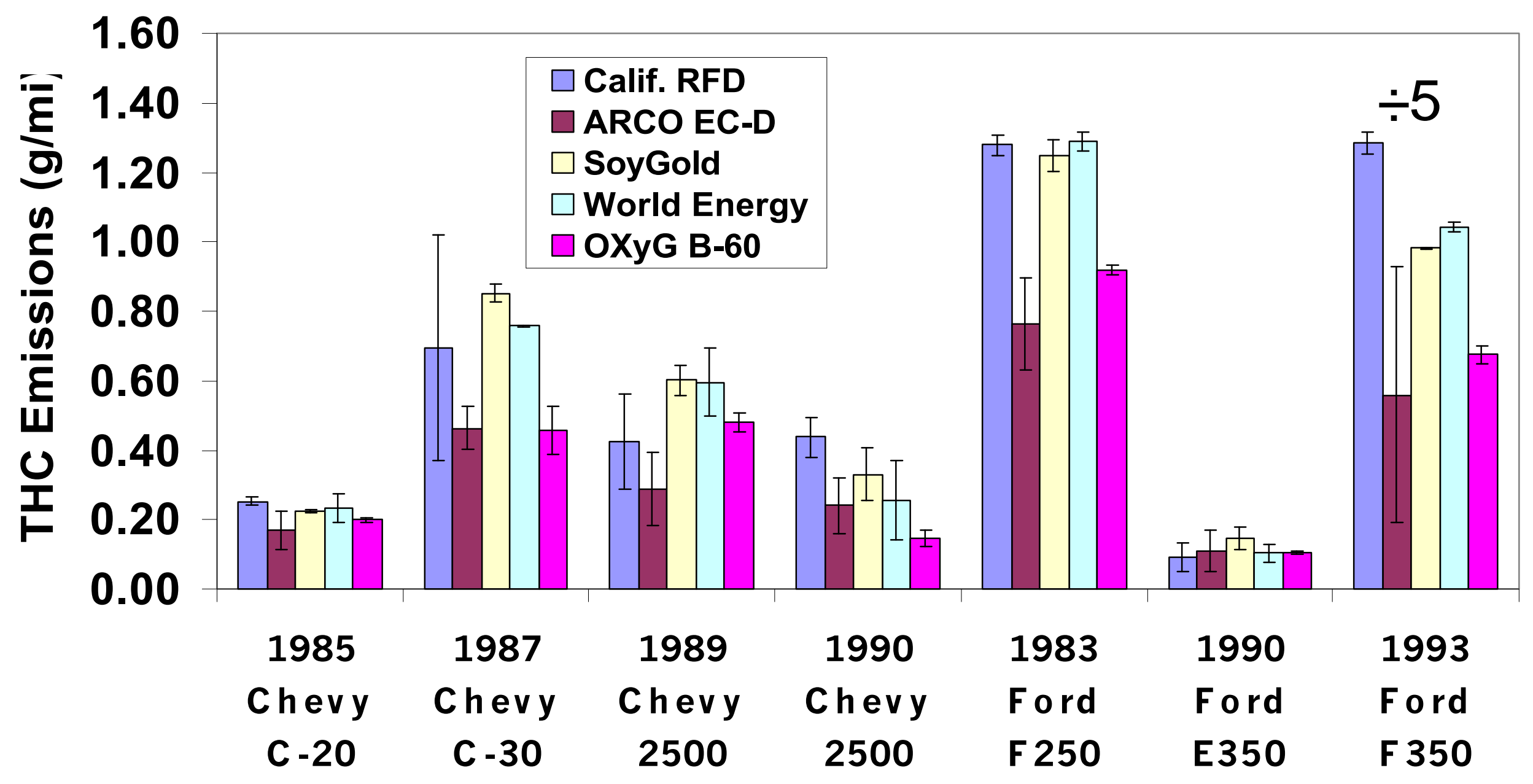


FTP CO Emissions

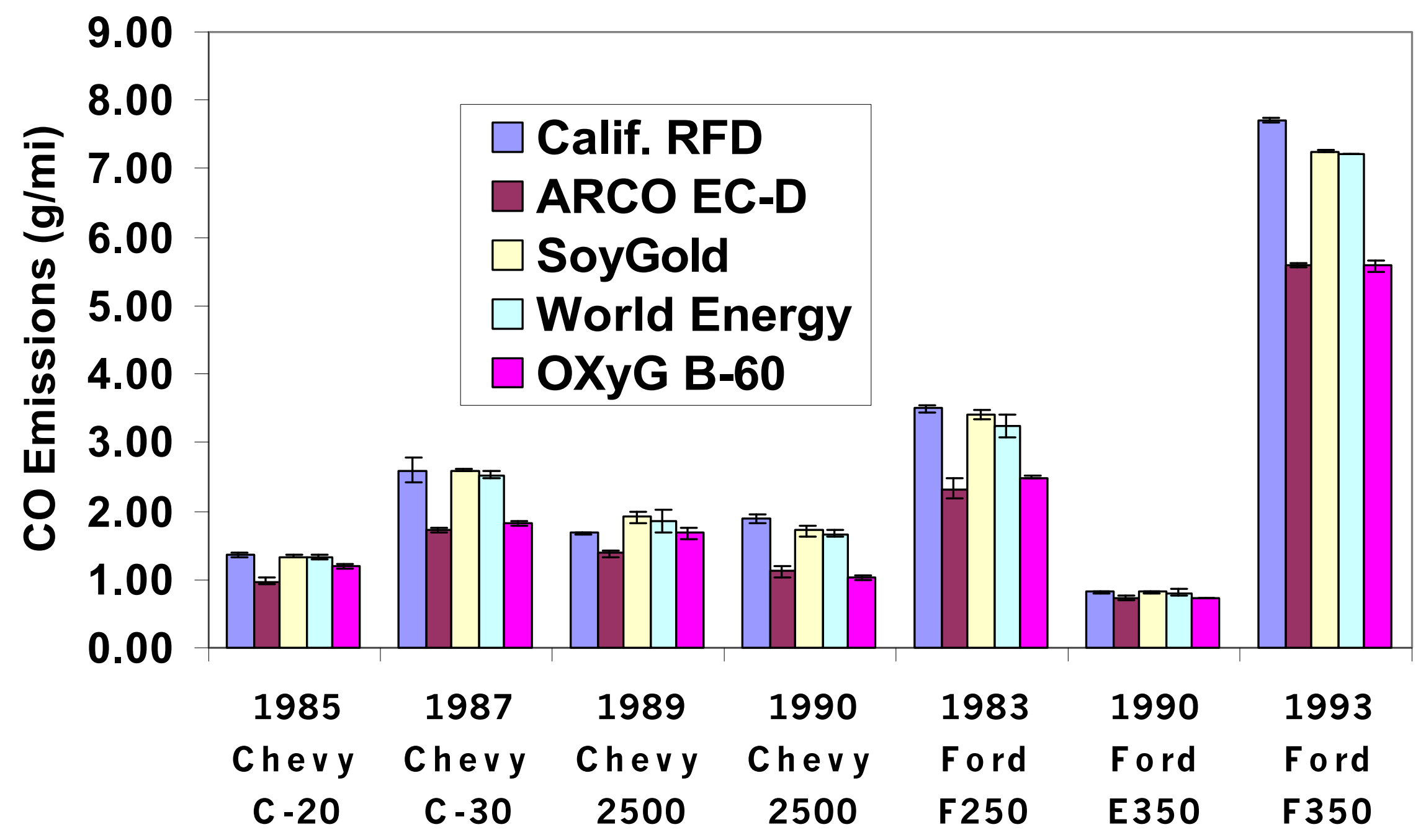


FTP PM Emissions

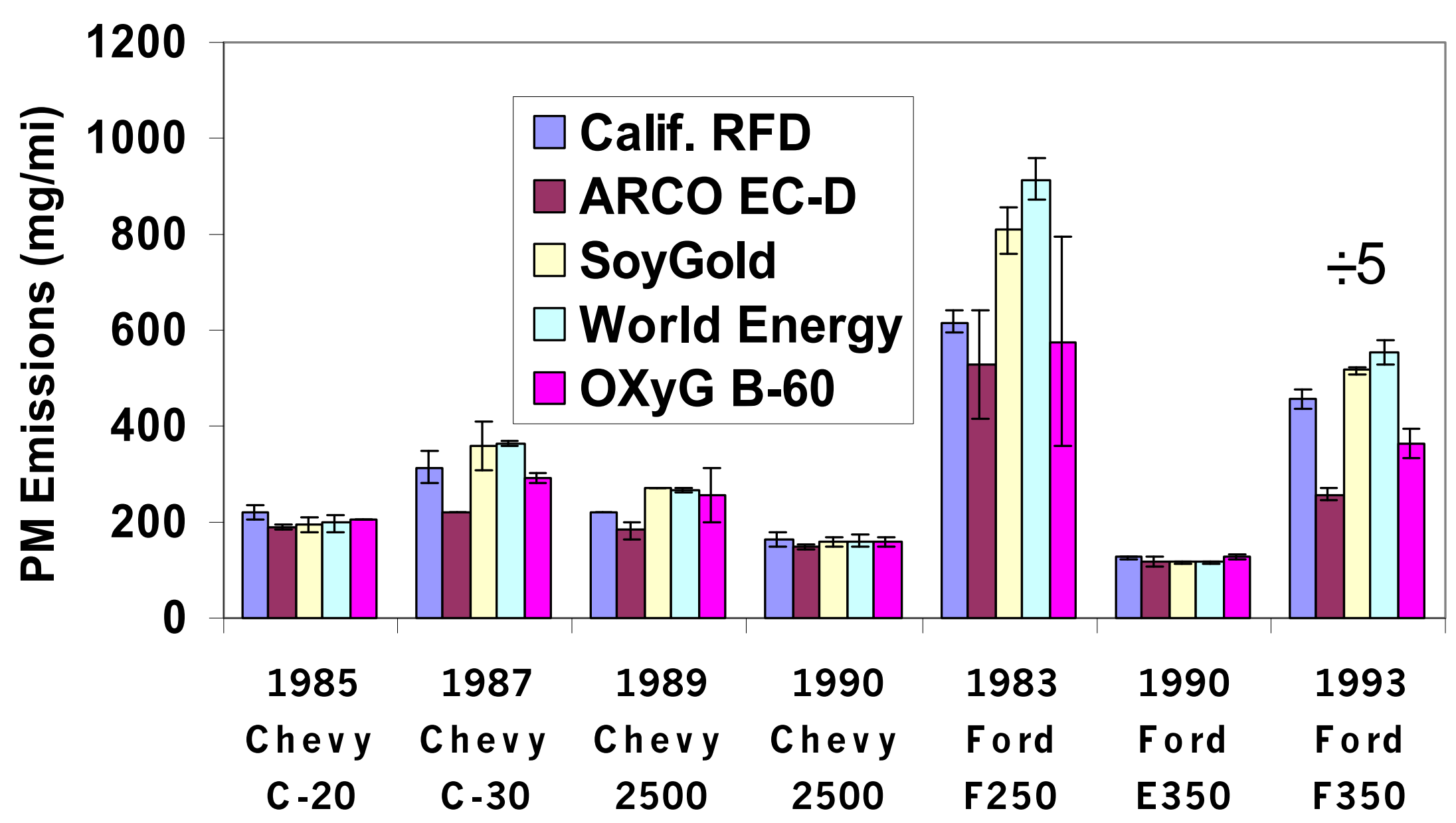




\section{FTP $\mathrm{NO}_{\mathrm{x}}$ Emissions}

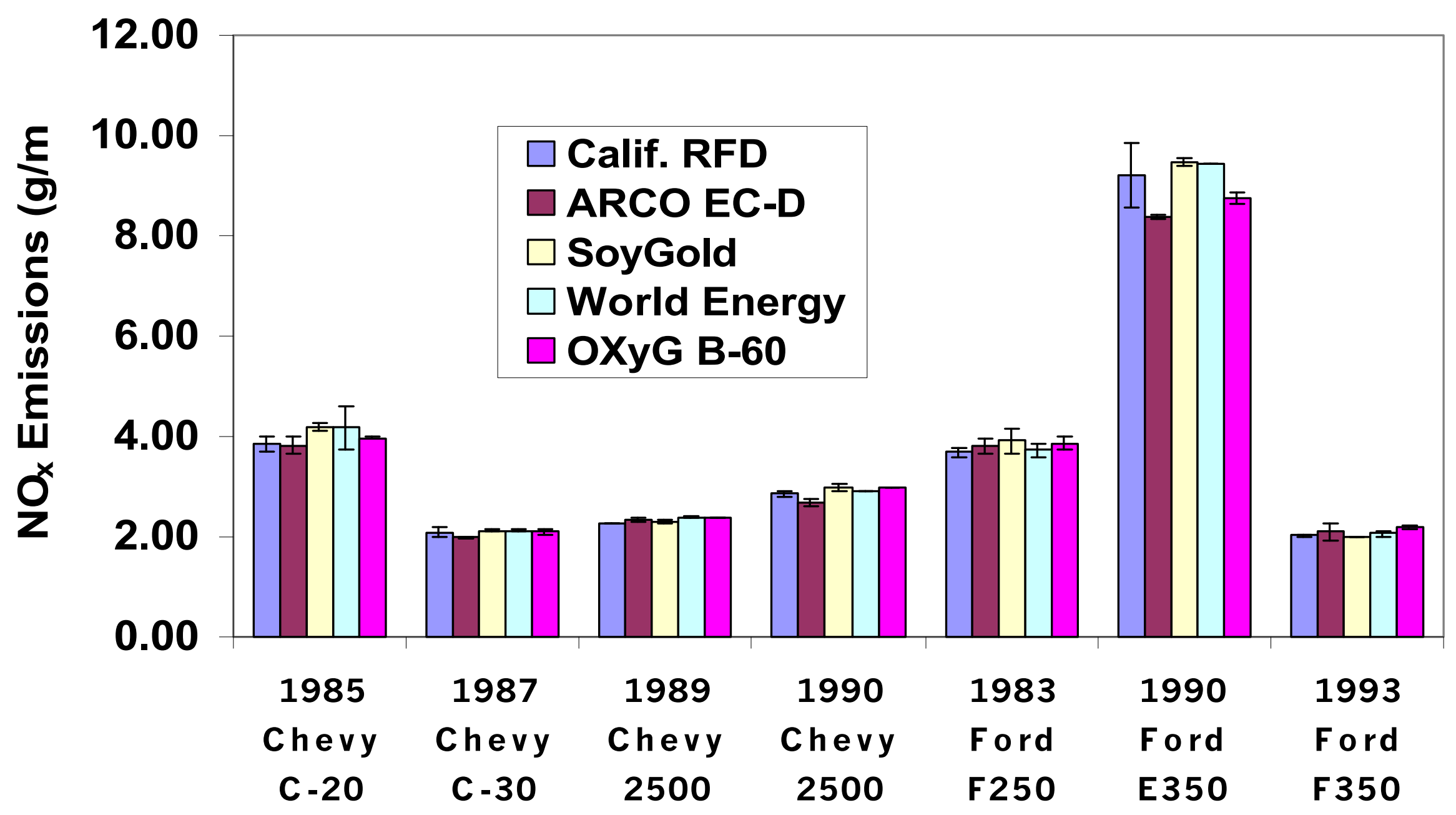

